\title{
A interpretação privativa da vida e a relação circular entre biologia e ontologia ${ }^{1}$
}

\author{
The privative interpretation of life and the \\ circular relation between biology and ontology
}

\section{Róbson Ramos dos Reis}

Doutor em Filosofia pela Universidade Federal do Rio Grande do Sul, professor associado III do Departamento de Filosofia e do Programa de Pós-Graduação em Filosofia da Universidade Federal de Santa Maria (UFSM), Santa Maria, RS - Brasil, e-mail: robsonramosdosreis@gmail.com

\section{Resumo}

Este artigo apresenta uma breve consideração da abordagem hermenêutica da natureza no projeto de Heidegger de uma ontologia fundamental. Apontase para uma diferença central na interpretação privada da vida em Ser e tempo e na abordagem circular dos organismos vivos em Os conceitos fundamentais da metafísica. Esta abordagem circular possui não apenas um significado metodológico, mas também um conteúdo positivo para a ontologia das ciências da vida. Tomando por base um conjunto de resultados experimentais e conceitos fundamentais da Biologia, a interpretação circular

1 Este trabalho recebeu o apoio do CNPq e foi submetido para a publicação nos Anais do I Congresso Luso-Brasileiro de Fenomenologia, Lisboa, 2007. 
apresenta o conceito de organismo nos termos de um círculo ambiental de desinibições pulsionais, no interior do qual os comportamentos animais exibem a estrutura da perturbação (Benommenheit). O principal resultado da hermenêutica da vida animal é a admissão de um limite na comensurabilidade possível entre a abertura para ser do humano e do animal.

Palavras-chave: Heidegger. Hermenêutica da natureza. Interpretação privativa.

\section{Abstract}

This paper presents a brief account of the hermeneutic approach of nature in Heidegger's project of a fundamental ontology. It points to a central difference in the privative interpretation of life in Being and time and the circular account of animal organisms in The fundamental concepts of metaphysics. The latter is not of methodological meaning only, but has a positive content for the ontology of the life sciences. Taking some experimental results and fundamental concepts from Biology as starting point, the circular interpretation presents the concept of organism in terms of a environmental ring of pulsional disinhibiting, in which the animal behavior shows the structure of the captivation (Benommenheit). The main result of the hermeneutic of animal life is the admission of a limit in the possible commensurability between the human and animal openness to beings.

Keywords: Heidegger. Hermeneutic of nature. Privative interpretation.

\section{Introdução}

\section{A ciência da vida e a interpretação privativa}

Em conformidade com a abordagem existencial de ciência introduzida por Heidegger em Ser e tempo, o exame dos supostos fundamentais que originam o descobrimento científico de um domínio dos objetos deve examinar as implicações ontológicas localizadas nos conceitos fundamentais de uma teoria. Nos conceitos fundamentais de uma teoria não estão apenas definições metodológicas e epistemológicas sobre o modo de acesso e verificação das descrições pretendidas. Mais do que isso, os conceitos fundamentais são os 
portadores de uma projeção ontológica sobre o que significa ser um caso ou instância do domínio de referência. Os procedimentos científicos de acesso, conceitualização, verificação e comunicação dependem da projeção do âmbito de objetos. Também a Biologia, como ciência de objetos - sobre os entes naturais vivos -, supõe um conjunto de estipulações sobre o seu domínio de referência. Ora, este contexto a priori não pode ser encontrado e determinado pela Biologia enquanto ciência positiva (HEIDEGGER, 1986, p. 56). Consequentemente, também para a Biologia há uma lógica produtiva da natureza viva, isto é, uma elucidação filosófica das projeções ontológicas da estrutura da vida.

De outro lado, ressalta Heidegger, o procedimento de investigação não pode ser a posteriori, reunindo, por exemplo, um material empírico e inferindo hipoteticamente estrutura ontológica. A razão é simples, num conceito hermenêutico de ciência não há puros fatos, pois estes somente podem ser acessíveis a partir de conceitos fundamentais com valência ontológica (HEIDEGGER, 1986 , p. 50). Heidegger menciona positivamente neste contexto os ensinamentos de Husserl acerca da filosofia científica como uma investigação a priori (HEIDEGGER, 1986, p. 50, n. 1). Husserl não apenas teria ensinado o sentido próprio do filosofar como investigação a priori, mas fornecido o ferramental adequado para esta pesquisa. Entretanto, Heidegger ressalta que a pesquisa a priori exige antes de tudo a adequada preparação do campo fenomenal, ou seja, não tanto a aceitação de uma construção a partir de uma intuição categorial e das reduções eidética e transcendental com vistas a uma fundamentação da ciência biológica. De que modo, então, estaria adequadamente preparado o solo fenomenal de onde se partiria para a elucidação hermenêutica dos fundamentos da Biologia? A resposta concisa e altamente problemática é oferecida nos seguintes termos: "na ordem de sua possível apreensão e interpretação, a Biologia como 'ciência da vida' se funda na ontologia do ser-aí, embora não exclusivamente nela” (HEIDEGGER, 1986, p. 49-50).

A relação de fundação aqui enunciada refere-se aos supostos ontológicos da Biologia, que deverão ser buscados em uma dupla direção: na ontologia do ser-aí e num contexto teórico diferente (embora este campo fundacional seja deixado sem nomeação e elaboração em Ser e tempo). De fato, é apenas nos Conceitos fundamentais da metafisica que a segunda via neste duplo fundamento da Biologia é tematizada. Mas como entender a relação de fundação entre os supostos ontológicos da Biologia e a ontologia do ser-aí? Não significa esta afirmação um antropocentrismo descabido, ou até mesmo a inversão da ordem comum nas relações de dependência entre entes vivos 
naturais? Não seria mais adequado dizer que a ontologia do ser-aí se funda numa ontologia da natureza viva? Não é artificial inverter a relação de dependência que existe entre o ser humano e a vida? Embora se possa conceder que a lógica produtiva da Biologia seja uma investigação filosófica a priori, ela não deveria proceder do mais simples e independente para o mais complexo e dependente, isto é, da vida para o ser-aí?

A resposta de Heidegger é decididamente negativa, não apenas ao afirmar diversas vezes a relação de fundação que vai do ser-aí para a ontologia da vida, mas ao introduzir uma operação metodológica que parece ser mais problemática ainda, a saber: a interpretação privativa. Diz Heidegger, imediatamente após a frase já citada:

A vida é um modo peculiar de ser, mas essencialmente acessível somente no ser-aí. A ontologia da vida se leva a cabo pela via de uma interpretação privativa; ela determina o que deve ser para que possa haver algo assim como apenas-ainda-viver (Nur-noch-leben). A vida não é uma pura subsistência (pures Vorhandensein) nem tampouco ser-aí. O ser-aí, por sua vez, não poderá ser determinado ontologicamente como vida (indeterminada do ponto de vista ontológico) e, ademais, outra coisa (HEIDEGGER, 1986, p. 50).

Um pouco adiante, referindo-se ao uso da noção de mundo circundante (Umwelt), Heidegger renova a dependência da Biologia em relação a uma lógica produtiva. Para que a estrutura do ter um mundo circundante possa ser elucidada como um a priori do domínio de objetos da Biologia, antes de tudo ela deva ter sido previamente conceitualizada como uma estrutura do ser-aí. A elucidação do mundo circundante como conceito fundamental para a Biologia supõe a elucidação de mundo e ser-no-mundo como estruturas ontológicas do ser-aí. E então ele afirma que "somente orientando-se pela estrutura ontológica assim concebida é que se poderá delimitar a priori, pela via da privação, a constituição ontológica da "vida"” (HEIDEGGER, 1986, p. 58).

Por fim, a operação privativa é novamente afirmada como procedimento metodológico para a ontologia da vida no fim da primeira seção da analítica existencial. Na apresentação do conceito de cuidado por relação às noções de ímpeto e inclinação (Drang und Hang), Heidegger afirma que estas noções podem ser predicadas da constituição ontológica de entes que apenas vivem (que não são meras coisas subsistentes, mas também não são ser-aí), e acrescenta: "a constituição ontológica fundamental do "viver" é, no entanto, 
um problema próprio, e este somente pode ser tratado, pela via de uma privação redutiva, a partir da ontologia do ser-aí" (HEIDEGGER, 1986, p. 194).

Dado que as expressões "interpretação privativa", "via privativa" e "privação redutiva" não são elucidadas, a palavra "privação" conduz facilmente a um equívoco exegético. Algumas das críticas ao suposto antropocentrismo de Heidegger são vítimas desta má-compreensão, que consiste em compreender a privação como uma operação abstrativa. Assim, primeiro seria determinado o que é o ser-aí humano, para depois abstrair redutivamente de suas características específicas. Na privação dos traços essenciais do ser-aí haveria uma abstração da qual resultaria a essência positiva da vida. Os organismos animais, por exemplo, seriam vistos sempre em figuras da falta: não possuir mundo, não poder morrer, não possuir logos, não ter acesso aos entes como entes, não ter abertura para o ente no todo, não ter mãos, não ter história, não morar, não ter espaço, não calcular, etc. (ELDEN, 2006). Pelo contrário, e antes disso, ser ser-aí significaria exatamente possuir todas estas estruturas e equipamentos. Em suma, a interpretação privativa seria o núcleo onde se esconderia o antropocentrismo e a metafísica no pensamento de Heidegger.

Esta compreensão da interpretação privativa é tão natural quanto equivocada (embora Heidegger tenha afirmado textualmente todas as mencionadas ausências próprias do mundo animal). Para identificar o erro que a governa deve-se prestar atenção ao sentido puramente metodológico que é atribuído por Heidegger à relação de fundação entre os fundamentos da Biologia e a ontologia do ser-aí. Associado a esta desatenção liga-se um desconhecimento do tratamento fenomenológico concedido para a operação de negação. Na Preleção sobre o Sofista, Heidegger introduziu a noção de uma negação mostrativa, que não é simplesmente a abstração formal de um atributo, formando um complemento, mas ainda mantém um vínculo mostrativo com a base da negação (REIS, 2003). O ponto relevante é que a negação operada sobre um ente qualificado como ser-aí - que não é determinado por propriedades, mas por possibilidades existenciais - não resulta na ausência de um atributo ou capacidade. Pode-se dizer, então, que a interpretação privativa consiste em antepor um obstáculo metodológico ao uso nivelado da operação de negação.

O significado metodológico da interpretação privativa consiste inicialmente em que ela não fornece nenhuma determinação material sobre o que é vida ou a essência dos organismos. Antes disso, ela oferece a orientação sobre como iniciar e proceder a uma interpretação ontológica da vida. Trata-se de uma prioridade da ontologia do ser-aí apenas no tocante à ordem de apreensão e interpretação, ou seja, para apreender e interpretar ontologicamente os 
fundamentos da Biologia é preciso ter realizado antes a interpretação ontológica da existência. Tendo assegurado uma correta ontologia do ser-aí, opera-se a interpretação privativa. Central neste contexto é a afirmação de que vida é um modo particular de ser, mas que somente é acessível no ser-aí. Sendo acessível no ser-aí, há a possibilidade fatal de que o modo de ser da vida seja submetido à dinâmica própria em que o ser-aí tem acesso aos entes e interpreta ser, isto é, esteja submetido à tendência ao encobrimento e ao nivelamento ontológicos.

O ser-aí humano, como nos é dado a conhecer na analítica existencial, possui a tendência intrínseca de conceber o todo dos entes de um modo nivelado. É possível que a vida seja concebida segundo o modo de ser dos entes não vivos, a natureza inanimada. Ou, segundo outra perspectiva, a vida pode ser concebida a partir do modo de ser dos utensílios, isto é, segundo uma teleologia externa. Mais ainda, a vida pode ser concebida com base em uma noção indiferenciada de totalidade, entendida como simples agregado ou soma. Neste contexto, a interpretação ontológica fica exposta a sofrer o influxo deste movimento arruinante e nivelador. A interpretação privativa significa que a ontologia da vida deve ser assegurada em contra das tendências niveladoras da compreensão cotidiana de ser. De outro lado, assim procedendo abre-se a possibilidade de uma redução fenomenológica, isto é, de que a vida seja tematizada no seu modo próprio de ser. Se a redução significa o orientarse para o sentido próprio do ser dos entes em questão, então a privação de formas não adequadas à natureza viva deve ser rigorosamente assegurada. Em última instância, porém, a via privativa é um instrumento hermenêutico dirigido não apenas para as tendências à transgressão interpretativa ínsitas no ser-aí humano, mas sobretudo para a retirada da alternativa entre idealismo e realismo, isto é, o complexo de problemas referentes ao isomorfismo supostamente implicado pela referência intencional a objetos (MCMANNUS, 2007, p. 84-85). Dito mais especificamente, a privação é proibitiva em relação à própria questão de se todos os entes acessíveis na abertura da existência estão ou não determinados pelo modo de ser do ser-aí.

Axel Beelmann (1994, p. 40-55) mostrou com suficiência que a interpretação privativa orienta-se contra aquela abordagem hierarquizante que concebe a natureza no seu todo como um conjunto de níveis progressivamente integrados nos estratos mais elevados e complexos. Os níveis superiores absorveriam os inferiores, e neste caso faria sentido proceder por abstração com o intuito de obter as determinações positivas dos níveis mais simples. Heidegger opõe-se frontalmente à concepção de Max Scheler, pela qual o ser humano deve ser concebido como a natureza viva mais alguma coisa: o espírito.

Rev. Filos., Aurora, Curitiba, v. 22, n. 31, p. 423-435, jul./dez. 2010 
A via privativa não interpreta o conceito de vida como sendo algo desprovido da condição de ser-aí. É a partir da ontologia do ser-aí que fica interditada uma reconstrução reducionista do conceito de vida, por exemplo, em termos do mecanicismo. De outro lado, na medida em que a ontologia do ser-aí mostra que a existência não é um predicado essencial acrescido à natureza viva, a interpretação privativa não opera a negação da propriedade de ser ser-aí, para que então restasse apenas o viver. A interpretação privativa previne não apenas contra o mecanicismo reducionista, mas igualmente contra hipóteses vitalistas que enxertariam um princípio especulativo na natureza inanimada.

Por outro lado, sendo o comportamento científico um modo de existir do ser-aí, também a investigação científica está exposta ao nivelamento, concretizado, por exemplo, na extrapolação injustificada dos supostos que permitem a medição. Assim, a matematização de um domínio de objetos é possível, mas, além disso, é preciso que as motivações para tal sejam justificadas. Na medida em que são corpos extensos, os seres vivos admitem certa determinação matemática. Porém, implementar ilimitadamente este procedimento significaria um desvio na orientação teleológica da própria investigação científica sobre os organismos. Seria, nas palavras de Heidegger, "um falseamento no propósito de conceber e determinar o organismo como tal" (HEIDEGGER, 1996, p. 43). É relevante notar que esta declaração implica que não há uma recusa pura e simples da aplicação do formalismo matemático no domínio da vida, mas sim de um uso desmedido cujas motivações não seriam justificadas. ${ }^{2} \mathrm{O}$ fetichismo pitagórico, segundo a expressão de McMannus (2007, p. 97-99), é uma importante transgressão hermenêutica a ser prevenida pela via da interpretação privativa na lógica produtiva da Biologia. Porém, os fundamentos ontológicos das ciências da vida não estão apenas metodologicamente delineados por restrições originadas no contexto da analítica da existência. É nos Conceitos Fundamentais da metafísica que encontramos a segunda linha de fundação ontológica, e esta sim contém a pretensão de oferecer determinações não puramente metodológicas a respeito do modo de ser dos organismos.

2 O uso de modelos matemáticos é um fato decisivo no desenvolvimento da biologia evolutiva, sobretudo na genética de populações. Este é um tópico bem conhecido na qualificação do possível caráter nomológico da Biologia, de acordo com o qual a natureza histórica da biologia evolutiva não seria incompatível com o uso de modelos matemáticos com estrutura hipotética (ver o exame do modelo matemático de Fisher em SOBER, 2000, p. 16-17). 


\section{Ontologia e ciência da vida}

Nos Conceitos fundamentais da metafísica, a indagação ontológica sobre os organismos animais está orientada para a elucidação do conceito de mundo. O procedimento comparativo enfrenta-se com dificuldades fundamentais que apontam para problemas metodológicos na investigação ontológica sobre os fundamentos da Biologia (HEIDEGGER, 1983, p. 264). Tais problemas são oportunos para identificar aquela abordagem da constituição ontológica da vida que não está fundada na ontologia do ser-aí.

A primeira dificuldade consiste em que nem a morfologia nem a fisiologia são aptas para vislumbrar o a priori da vida, precisamente porque elas já o supõem na pesquisa positiva (HEIDEGGER, 1983, p. 268). Além disso, estrutura da animalidade, por exemplo, não é o resultado de uma tematização observacional, pelo simples fato de que as observações são sempre específicas, e não de algo em geral (por exemplo, a animalidade enquanto tal). Tampouco o comportamento sob observação é acompanhado de alguma narrativa originada do próprio objeto observado, e mesmo que as expressões animais possam ser recebidas e comunicadas, elas sempre estarão atravessadas pelas interpretações do investigador (HEIDEGGER, 1983, p. 268). Duas perguntas fundamentais são deixadas sem resposta: sob qual aspecto são acessíveis os organismos animais, e de que maneira eles são acessíveis de modo originário? No entanto, a comparação entre a pobreza, a falta, e a formação de mundo exige uma resposta para estas perguntas. Esta resposta, diz Heidegger, tem um caráter provisório e não vinculante, ao manter a expectativa de que o sucesso na interpretação comparativa permita elucidar ou mesmo responder àquelas perguntas (HEIDEGGER, 1983, p. 268). Para se chegar à essência da vida é preciso supor certa concepção geral acerca da própria vida e acerca do modo de sua interpretação (HEIDEGGER, 1983, p. 297). A circularidade é evidente, e não será elidida. Ao contrário, a circularidade é assumida como o movimento autêntico da investigação filosófica e no exame da relação entre ontologia e ciência.

Deste modo, a proposição "O animal é pobre em mundo" refere-se ao campo próprio da Zoologia, mas não é obtida ou confirmada pelos resultados da pesquisa zoológica. Porém, ela não pode ser elucidada sem uma orientação obtida da Biologia e da Zoologia. Como proposição essencial, ela indica o a priori da constituição do domínio dos objetos zoológicos, e, embora não tenha a medida de sua verdade retirada da pesquisa biológica, não pode desconsiderar os resultados da Zoologia (HEIDEGGER, 1983, 
p. 274-276). ${ }^{3}$ Esta condição introduz complexidade e ambiguidade no procedimento. De um lado, a investigação filosófica não pode prescindir dos resultados especializados, mas de outro, com eles não está dado o critério da correção ontológica.

Pode-se afirmar que a interpretação da constituição ontológica da vida opera de modo circular, não em sentido lógico ou causal, mas em uma acepção por assim dizer topográfica (MALPAS, 2007, p. 125-126). O modo como se compreende o procedimento circular determina o que é o progresso no conhecimento, na Ciência em geral, e na Filosofia. $\mathrm{O}$ entendimento comum, diz Heidegger, permanece apenas na periferia do círculo, isto é, o percorre como se fosse uma linha reta. Deste modo, chega-se sempre no mesmo ponto, e não há deslocamento progressivo no saber. $\mathrm{O}$ entendimento filosófico, por sua parte, não apenas entra no círculo, mas o percorre com o olhar voltado para o centro. Girando em torno do centro, abrem-se diferentes perspectivas de visualização, e é deste modo que o centro chega a ser mais determinado (HEIDEGGER, 1983, p. 266-267, p. 276-277). Os diferentes pontos de vista assumidos ao circular em torno do centro alteram fundo e frente, oferecendo uma visão mais determinada da relação entre condição e condicionado. Em resumo, pode-se afirmar que além da interpretação privativa, os fundamentos ontológicos da Biologia são obtidos por meio de uma interpretação circular. Trata-se de lançar mão, de modo não vinculante e provisório, de algumas suposições sobre a estrutura dos organismos, para colocá-las em novo prisma a partir de noções e resultados experimentais da Biologia. É este procedimento que justifica a afirmação de que a proposição sobre a pobreza de mundo dos animais é admitida e resta apenas como um problema (HEIDEGGER, 1983, p. 396). Este problema, por sua vez, permite visualizar outros problemas estruturais acerca do âmbito da vida. ${ }^{4}$

Não é infundado concluir que a interpretação privativa e giro circular em torno de resultados teóricos e experimentais da Biologia retiram o sentido quase poético do enunciado sobre a pobreza em mundo. Além disso, é

3 Este é um dos poucos momentos, caso não seja o único, em que Heidegger admite explicitamente uma relação cooperativa e não hierárquica entre Filosofia e Ciência, e que representa um traço característico do procedimento hermenêutico no tocante à abordagem filosófica da investigação científica (De BEISTEGUI, 2006; WINKLER, 2007, p. 532-532).

4 Com esta base metodológica, Heidegger não apenas evita o dilema entre mecanicismo e vitalismo, como também se afasta do modelo hierárquico e integrativo de Max Scheler (HEIDEGGER, 1983, p. 283). 
esta mesma base que orienta a interpretação da vida animal por uma recusa da comparação construtiva com a formação humana de mundo. De acordo com ela, seria possível iniciar com a explicitação da formação de mundo e, com base nas estruturas obtidas, examinar a carência específica dos organismos. Como sabemos, Heidegger executa outra operação, que consiste em dirigir-se para o domínio dos organismos animais, na tentativa de alcançar uma transposição para o interior deste campo (HEIDEGGER, 1983, § 49). A pergunta difícil que é formulada atinge o modo próprio em que os animais podem ter estados intencionais ou um acesso a algo (CARMAN, 2003, p. 45-52). Esta base conduz à Zoologia, por um lado, mas oferece um resultado ontológico decisivo e surpreendente, segundo o qual os organismos animais apresentam uma abertura para algo, ao mesmo tempo em que recusam uma completa transposição humana para o interior de sua abertura. ${ }^{5}$ Como já foi sugerido na literatura, esta recusa significa que a pobreza em verdade é característica do ser-aí humano (WINKLER, 2007).

O exame crítico de certas doutrinas sobre o organismo animal é claramente apresentado por Heidegger. Resulta deste exame uma dupla limitação. De um lado, a totalidade específica segundo a qual os organismos devem ser descritos impede a definição da vida orgânica em termos puramente celulares. De outro lado, organismos também não podem ser representados com os termos de uma teleologia externa que os aproximasse dos mecanismos (HEIDEGGER, 1983, p. 311). Autorregulação, autoprodução, autodireção e autorrenovação são características que se integram à dependência dos órgãos em relação às aptidões (HEIDEGGER, 1983, p. 339-340). Desse modo, as aptidões devem ser vistas como a base a partir da qual procede a organogênese. Associada ao conceito de aptidão está a noção de pulsão, a partir da qual é introduzido o conceito de perturbação (benehmen, Bennomenheit). Chega-se, assim, a um conceito básico de vida animal, segundo o qual os organismos animais são perturbados por elementos que desinibem as pulsões exercidas nas aptidões orgânicas. O organismo encontra uma adaptação no seu círculo envoltório, e pode ser adicionalmente conceitualizado como sendo uma luta pelo seu respectivo círculo de desinibições. Além disso, a estrutura do organismo não reside na configuração ou na regulação morfológica e fisiológica de forças, mas sim na aptidão para o envolvimento no círculo de desinibições. Com a absorção na atividade pulsional há uma abertura para algo, mas sempre

5 McNeill (2006, p. 17-24) acentuou com razão a importância deste movimento para o debate em torno do suposto antropocentrismo de Heidegger.

Rev. Filos., Aurora, Curitiba, v. 22, n. 31, p. 423-435, jul./dez. 2010 
no interior de um círculo de desinibição. A perturbação significa, portanto, uma privação na abertura para os entes. $\mathrm{O}$ organismo animal pode ser descrito como dotado da capacidade de perturbação diante de algo, mas seria uma transgressão categorial representá-lo como capaz de um comportamento para com algo como algo. Este é um resultado de Ser e tempo: a estrutura intencional do algo como algo requer a intencionalidade originária para ser, a compreensão de ser.

\section{Considerações finais}

A título de conclusão, destacamos duas consequências gerais da interpretação ontológica dos organismos. Primeiro, os organismos animais têm acesso e abertura para algo, mesmo que apenas no interior do círculo de desinibições. Estes círculos se sobrepõem, formando uma articulação na qual até mesmo o mundo humano está inserido. Na medida em que a transposição humana para círculo da vida animal nunca é completa e totalmente comensurada, então não se pode concluir que os organismos humanos e não humanos partilhem um mesmo conjunto de objetos intencionais. A interpretação privativa também impede que se interprete a intencionalidade animal como referida a simples coisas, tal como pode ser o caso na intencionalidade propriamente humana. Esta é a base para a crítica ao darwinismo que está rapidamente indicada nos Conceitos (HEIDEGGER, 1983, p. 263). Na noção de adaptação estaria presente implicitamente uma concepção dos animais como coisas dadas que se relacionam com seu ambiente na forma de comportamentos para com coisas simplesmente dadas, com coisas meramente subsistentes. A objeção referese ao sentido indeterminado em que é pensado o componente relacional da adaptação, na medida em que a intencionalidade adaptativa é concebida como sendo em relação a coisas simplesmente dadas (HEIDEGGER, 1983, p. 277).

Em segundo lugar, nos organismos animais a natureza torna-se presente para o ser-aí humano, revelando-se como subtraída da abertura formativa de mundo. Nos círculos envoltórios acontece uma dinâmica de incorporação, em que cada organismo adapta a si algo do ambiente. A natureza viva é o movimento de edificação sobre si mesma que estabelece formas diferenciadas de vigência e preponderância, e em relação às quais a abertura humana de mundo não consegue penetrar. Consequentemente, não é possível admitir a priori um integral compartilhamento nas diferentes aberturas para os entes que devem ser reconhecidas como próprias tanto da intencionalidade humana quanto orgânica. 
Estas conclusões revelam o alcance geral da hermenêutica da natureza descoberta na tematização cientifica. O movimento de incorporação e elevação da natureza sobre si mesma implica uma limitação para o projeto da ontologia fundamental, pois a temporalidade originária não é suficiente para interpretar a abertura própria à vida animal. Além disso, também os domínios naturais não podem ser simplesmente acumulados como regiões justapostas de entes (HEIDEGGER, 1983, p. 404). Caso esta reconstrução seja admissível, então também é preciso reconhecer a relevância das questões de fundamentos nas ciências naturais para o desdobramento interno do projeto ontológico de Heidegger. Assim como a física atômica promoveu um abalo na tese da projeção matemática da natureza, as noções originadas na Biologia conduzem para uma restrição ainda maior no projeto da ontologia fundamental. Olhando nesta direção somos obrigados a reconhecer um importante problema metateórico para a hermenêutica da natureza, um problema semântico. Quais a condições do dizer com sentido a vida e os organismos animais, se os seus fundamentos ontológicos nos são parcialmente inacessíveis? Não apenas isso, as limitações do essencialismo biológico e o reconhecimento do assim chamado pensamento populacional (MAYR, 1980) impõem uma revisão no conceito de organismo tal como elucidado por Heidegger? E se a estrutura ontológica da vida não puder ser interpretada apenas com base no conceito de organismo, mas tenha que incorporar as noções de população, e - a partir do conceito de evolução - as noções de replicadores (genes), veículos (organismos) e cadeias de replicadores copiados? Embora não tenhamos respostas para estes problemas, pretendemos que eles são incontornáveis para o projeto de uma hermenêutica da natureza.

\section{Referências}

BEELMANN, A. Heideggers hermeneutischer Lebensbegriff. Würzburg: Königshausen \& Neumann, 1994.

DE BEISTEGUI, M. Philosophie et biologie dans un esprit de "coopération". Noesis, n. 9, 2006. Disponível em: <http://noesis.revues.org/document281.html>. Acesso em: 30 jun. 2010.

CARMAN, T. Heidegger's analytic. Cambridge, UK: Cambridge University Press, 2003. 
ELDEN, S. Heidegger's Animals. Continental Philosophy Review, v. 39, n. 3, p. 273291, 2006.

HEIDEGGER, M. Die Grundbegriffe der Metaphysik. Welt - Endlichkeit Einsamkeit. Frankfurt am Main: Vittorio Klostermann, 1983.

HEIDEGGER, M. Sein und Zeit. 17. Aufl. Tübingen: Max Niemeyer Verlag, 1986.

HEIDEGGER, M. Einleitung in die philosophie. Frankfurt am Main: Vittorio Klostermann, 1996.

McMANUS, D. Heidegger, measurement and the 'intelligibility' of science. European Journal of Philosophy, v. 15, n. 1, p. 82-105, 2007.

McNEILL, W. The time of life. New York: State University of New York Press, 2006. MALPAS, J. Heidegger's Topology of being. In: CROWELL, S. G.; MALPAS, J. Transcendental Heidegger. Stanford: Stanford University Press, 2007. p. 119-134.

MAYR, E. Typological versus population thinking In: SOBER, E. (Ed.). Conceptual issues in evolutionary biology. 3rd ed. Cambridge, MA: MIT Press, 2006. p. 325-328.

REIS, R. Elementos de uma interpretação fenomenológica da negação. O Que Nos Faz Pensar, Rio de Janeiro, v. 17, p. 73-98, 2003.

SOBER, E. Philosophy of biology. 2nd ed. Boulder: Westview Press, 2000.

WINKLER, R. Heidegger and the question of man's poverty in world. International Journal of Philosophical Studies, v. 15, n. 4, p. 521-539, 2007.

Recebido: 30/07/2010

Received: 07/30/2010

Aprovado: $28 / 08 / 2010$

Approved: 08/28/2010 